\title{
Long term follow up of radiosynovectomy with yttrium-90 silicate in haemophilic haemarthrosis
}

\author{
M E E van Kasteren, I R O Nováková, A M Th Boerbooms, J A M Lemmens
}

\begin{abstract}
Objectives-The aim of this study was to evaluate the long term effect of radiation synovectomy with yttrium-90 silicate in haemophiliac patients with recurrent haemarthrosis.

Methods-The bleeding frequency and the mobility of the joint were recorded in 16 joints of 14 patients 1 year before radiosynovectomy and during follow up, which ranged from 3 to 6 years. Patients evaluated the effect of their own treatment by completing a questionnaire. Radiographs of the joints were scored by an independent radiologist before treatment.

Results-A satisfactory reduction of the frequency of haemorrhage was achieved in $94 \%$ of joints during the first year after treatment and was maintained in $63 \%$ until the end of the follow up period. In general there was no decrease in mobility attributable to radiosynovectomy, and the patients' own evaluations agreed with the evaluations based on the frequencies of haemarthrosis in $75 \%$. Patients who had only minor, or no, radiological abnormalities of the joints before treatment showed the best results. One patient developed synovitis as a complication of the radiosynovectomy.
\end{abstract}

Conclusion-Radiosynovectomy is an effective and safe treatment for recurrent haemarthrosis in haemophiliac patients, especially in those who have joints with no or minor radiological damage.

Department of

Haematology,

University Hospital

Nijmegen,

The Netherlands

$M E$ E van Kasteren

I R O Nováková

Department of

Rheumatology,

University Hospital

Nijmegen,

The Netherlands

A M Th Boerbooms

Department of

Radiology,

University Hospital

Nijmegen,

The Netherlands

J A M Lemmens

Correspondence to:

Dr I R O Nováková,

Department of Haematology,

University Hospital

Nijmegen,

PO Box 9101,

6500 HB Nijmegen

The Netherlands.

Accepted for publication 16 February 1993
(Ann Rheum Dis 1993; 52: 548-550)

Recurrent haemarthrosis causes joint damage that seriously impairs the quality of life of haemophiliac patients. Joints are vulnerable as a result of low levels of thromboplastin in synovial tissue and a lack of circulating clotting factor. ${ }^{1}$ Consequently, bleeding may occur spontaneously and after a minor trauma. Blood irritates the joint and causes a synovitis that enhances recurrent bleeding, finally leading to synovial fibrosis, haemosiderosis, and rigidity of the synovial membrane and joint capsule. ${ }^{23}$ Reducing the frequency of haemorrhage appears to be the only possibility to postpone the development and progress of haemophilic arthropathy. ${ }^{14}$ Recurrent bleeding in a single joint requires local treatment to diminish the amount of blood products. Radiosynovectomy is used to manage chronic synovitis, ${ }^{5-7}$ and is successful because it causes initial inflammation and necrosis of the synovial membrane, followed by fibrosis. In haemophiliac patients this renders the synovia less vulnerable and interrupts the vicious circle of haemarthrosis and synovitis. The technique therefore offers an alternative to conservative treatment and surgical synovectomy. We present the results of a retrospective evaluation of radiosynovectomy with yttrium-90 silicate in patients with haemophilia, who had recurrent bleeding in the same joint.

\section{Patients and methods}

From 1980 to 1990 radiosynovectomy with yttrium-90 silicate $\left({ }^{90} \mathrm{Y}\right)$ was performed in 21 joints in 19 patients who had had at least three bleedings per annum in a single joint and who had given informed consent. The follow up period ranged from 3 to 6 years, except when prophylaxis with clotting factor concentrate was started. Before treatment and during years thereafter, haemarthrosis and joint mobility were recorded. Radiographs obtained before treatment were scored according to Pettersson ${ }^{8}$ by an independent radiologist. Patients completed a questionnaire at the end of follow up in which they were asked about the effect of radiosynovectomy on the frequency of bleeding, pain, articular mobility, and activities of daily living.

The clotting deficiency was corrected before treatment and during the following three days in order to reach clotting factor activity of $50 \%$. Before intra-articular administration of ${ }^{90} \mathrm{Y}$ contrast fluid was injected into the joint under radiographic control to ensure that the needle was correctly positioned. ${ }^{6}$ The dosage of ${ }^{90} \mathrm{Y}$ was $2 \mathrm{mCi}(74 \mathrm{MBq}$ ) for the wrist, elbow, and ankle and $5 \mathrm{mCi}(185 \mathrm{MBq})$ for the knee. Within 24 hours after the injection, frontal and lateral scintigraphy were performed to chẹck the distribution of the radioactive material in the joint. Following injection, the joint was immobilised by an elastic bandage and patients were confined to bed for 3 days. The frequency of haemarthrosis during the first and third year after treatment was compared with that which occurred during the year before radiosynovectomy. The average frequency of haemarthrosis during the follow up period was also assessed. The outcome was considered good if haemarthrosis decreased by $50-100 \%$, moderate when the decrease was $25-49 \%$, and failure when there was a reduction of less than $25 \%$. The results of the questionnaire were also classified in similar terms. 
Table 1 Evaluation of treatment

\begin{tabular}{|c|c|c|c|c|c|c|c|c|c|}
\hline \multirow[t]{2}{*}{ foint No } & \multirow[t]{2}{*}{ foint } & \multicolumn{7}{|c|}{ Frequency of haemarthrosis before $(0)$ and yearly after the treatment } & \multirow[t]{2}{*}{ Results according to patient } \\
\hline & & 0 & 1 & 2 & 3 & 4 & 5 & 6 & \\
\hline 1 & Knee & 8 & 9 & 9 & 11 & 7 & & & Failure \\
\hline 2 & Knee & 6 & 0 & 2 & 5 & 5 & 6 & & Moderate \\
\hline 3 & Knee* & 7 & 0 & 0 & 5 & 2 & 4 & 10 & Moderate \\
\hline 4 & Kneet & 6 & 0 & 0 & 2 & & & & Moderate \\
\hline 5 & Knee & 6 & 1 & 3 & 1 & 2 & 2 & & Good \\
\hline 6 & Knee $^{\star} t$ & 6 & 1 & 0 & 0 & 0 & 0 & & Good \\
\hline 7 & Knee & 9 & 1 & 0 & 0 & 0 & & & Good \\
\hline 8 & Knee & 12 & 1 & 1 & 0 & 6 & 0 & 0 & Good \\
\hline 9 & $\mathrm{Knee}^{\star}$ & 8 & 0 & 0 & 0 & 0 & & & Good \\
\hline 10 & Kneet & 3 & 0 & 0 & 0 & 0 & 0 & 0 & Good \\
\hline 11 & Ankle & 7 & 1 & 4 & 5 & 7 & & & Good \\
\hline 12 & Ankle & 4 & 0 & 2 & 2 & 2 & 1 & 6 & Good \\
\hline 13 & Elbow* & 14 & 2 & 0 & 0 & 0 & 0 & 0 & Moderate \\
\hline 14 & Elbow & 6 & 1 & 3 & 4 & 5 & & & Moderate \\
\hline 15 & Elbow & 14 & 4 & 3 & 5 & & & & Good \\
\hline 16 & Wrist & 24 & 0 & 0 & 0 & 2 & & & Good \\
\hline
\end{tabular}

${ }^{\star}$ Clotting factor prophylaxis before the treatment; $†$ Factor VIII inhibitor present.

\section{Results}

Five patients could not be evaluated, three because of insufficient data, one because follow up was inadequate, and in another, clotting factor prophylaxis was used to treat recurrent haematuria. Sixteen joints were therefore assessed involving 14 patients whose ages ranged from 7 to 46 years (mean 28). Ten patients, of whom three had factor VIII inhibitor, had haemophilia $A$, three had haemophilia B and one had factor VII deficiency. Five patients were treated prophylactically with a clotting factor preparation before radiosynovectomy without any influence on the bleeding frequency (table 1). After radiosynovectomy, prophylaxis was discontinued at the request of one patient. The average number of bleedings in the year before the radiosynovectomy was 8.8 (SD 5.2) which decreased markedly for 3 years after treatment. The patients reported good results in the questionnaire in 10 of 16 radiosynovectomies. The reduction in bleeding frequency was considered good in 15 joints after 1 year (table 2). In five joints which initially had a satisfactory outcome the bleeding frequency increased steadily with time, ultimately resulting in failure of the treatment.

After a year, nine of the 16 joints showed improved mobility of more than $10^{\circ}$ whereas it remained unchanged in four joints. In one case, joint movement decreased by $45^{\circ}$ owing to bleeding soon after treatment and by $10^{\circ}$ in another because of injury. There was no clear explanation for a third patient in whom mobility was reduced by $10^{\circ}$. After 3 years data on mobility were available in 14 cases: there was still improvement in nine joints (average $15^{\circ}$ ), no change in three, and a decrease of $35^{\circ}$ and $20^{\circ}$, respectively, in two cases.

Fourteen of the 16 radiographic examinations were available for this study. Eight joints with a Pettersson score less than four

Table 2 Evaluation according to investigator

\begin{tabular}{llll}
\hline Period & \multicolumn{3}{l}{ Outcome } \\
\cline { 2 - 4 } & Good & Moderate & Failure \\
\hline 1 Year & 15 & 0 & 1 \\
3 Years & 10 & 4 & 2 \\
At the end & 10 & 0 & 6 \\
\hline
\end{tabular}

before treatment showed a good result 3 years after treatment. In contrast, five joints with a Pettersson score of more than four before treatment showed only a moderate improvement, while one case was deemed a failure. There was only one complication caused by an unequal distribution of ${ }^{90} \mathrm{Y}$, which resulted in a severe synovitis

\section{Discussion}

There have been some reports about the short term effect of radiosynovectomy on the frequency of haemarthrosis in haemophiliac patients $^{9-12}$ but, as far as we know, none on the long term evaluation of this treatment. In common with published data, a good initial response was noted in our centre during the first year after treatment. Thereafter the frequency of bleeding increased in five of the 15 responders, but a satisfactory response was maintained in the other 10 joints for 3 years and in some for 6 years. Two thirds of patients reported treatment to have been satisfactory and all but four were in agreement with the investigators' evaluation. The discrepancy might be explained by the fact that the patients took other factors into account, including change in pain, mobility, and functional capacity. The articular mobility did not deteriorate appreciably after radiosynovectomy, which compares favourably with surgical synovectomy.

The results indicated that the likelihood of a favourable response was higher in joints with no or little radiological damage, similar to the findings in patients with rheumatoid arthritis. ${ }^{6}$ As patients are often treated at a relatively young age, the risk of radiation exposure should be kept in mind. In our hospital the joint was immobilised after the injection for 3 days to reduce leakage of radioactive material, thereby lowering the risk of potential damage. ${ }^{1314}$ The total body radiation load due to leakage of ${ }^{90} \mathrm{Y}$ in the knee joint was calculated to be $0.8 \mathrm{cGy},{ }^{6}$ (the inguinal nodes and knee joint excluded), which is comparable with the effective dose equivalent of urography $(1.8 \mathrm{cGy}) .^{15}$ After 30 years of radiosynovectomy treatment in rheumatology, no increased incidence of cancer or congenital abnormalities has been reported. On the other 
hand, the advantages of radiosynovectomy over surgical synovectomy include a shorter stay in hospital, less requirement for clotting factor, shorter rehabilitation, no anaesthesia, no increase of joint mobility, and the simplicity of the procedure, making it an attractive method of treatment of recurrent bleedings in haemophiliac patients.

Our data suggest that radiation synovectomy is an effective and safe treatment of recurrent articular bleeding in haemophiliac patients, especially in joints with no or minor radiological damage.

1 Heynen L. Haemophilic arthropathy; subscript of the joint status of haemophilic patients comparing prophylactic replacement therapy with on demand. Leiden: Leiden University, 1986. [Thesis.]

2 Sokoloff L. Biochemical and physiological aspects of degenerative joint diseases with special reference to hemophilic arthropathy. Ann NY Acad Sci 1975; 240: 285-90.

3 Madhok R, York J, Sturrock R D. haemophilic arthritis. Ann Rheum Dis 1991; 50: 588-91.

4 Creveld S, Hoedemaker Ph J, Kingma M J, Wagenvoort C A. Degeneration of joints in haemophiliacs under treatment by modern methods. F Bone foint Surg $[\mathrm{Br}]$ 1971; 53: 296-302.
5 Gumpel J M. The role of radiocolloids in the treatment of arthritis. Rheum Rehabil 1974; 1: 1-9.

6 Boerbooms A M Th, Buijs W C A M. Danen M, vd Putte L B A, Vandenbroucke J P. Radiosynovectomy in chronic synovitis of the knee joint in patients with rheumatic synovitis of the knee joint in patients

7 Franssen M J A, Boerbooms A M Th, Karthaus R P Buijs W C A M, vd Putte L B A. Treatment of pigmented villonodular synovitis of the knee with yttrium-90 silicate prospective evaluation by arthroscopy, history, histolog and ${ }^{99 \mathrm{~m}} \mathrm{Tc}$ pertechnetate uptake measurements. $A n$ Rheum Dis 1989; 48: 1007-13.

8 Pettersson H Ahlberg A, Nilsson L M. A radiological classification of haemophilia arthropathy. Clin Orthop 1980; 149: 153-9.

9 Michel G, Rogez J M, Guihard D, Letenneur J. Synoviortheses a l'yttrium 90 dans les arthropaties Synoviortheses a lyttrium 90 dans les arthropaties

10 Pad Bosch P J I, vd Putte L B A, Boerbooms A M Th Geerdink P J. Radiosynoviorthesis in haemophilia join disease. $Z$ Rheumatol 1981; 40: 237-9.

11 Fernandez-Palazzi F, Bosch N B, Vargas A F. Radioactive synovectomy in haemophilic haemarthrosis, follow-up of fifty cases. Scand $\mathcal{F}$ Haematol 1984; 33 (suppl 40): 291-300.

12 Ahlberg A, Pettersson H. Synoviorthesis with radioactive gold in hemophiliacs; clinical and radiological follow-up. Acta Orthop Scand 1979; 50: 513-7.

13 De la Chapelle A, Oka M, Rekenes A, Ruotsi A. Chromosome damage after intra-articular injection of radioactive ytrium: effect of immobilisation on the radioactive yttrium: effect of immobilisation

14 Roberts S D, Gillespie P J. Effect of immobilisation on retention of 90 yttrium. Ann Rheum Dis 1973; 32 (suppl): $46-7$.

15 Jankowski J. Organ doses in diagnostic X-rays procedures. Health Phys 1984; 46: 228-34.

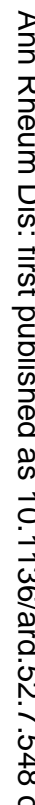

